\section{General Anesthesia for an Oral Surgical Procedure in a Patient with Severe Heart Valve Disease Scheduled for Cardiac Surgery: A Case Report}

\author{
Hitomi Satomi ${ }^{1}{ }^{(D *}$, Noriya Hirose ${ }^{2}$, Shunichi Oka ${ }^{1}$ and \\ Yoshiyuki $\mathrm{Oi}^{1}$
}

${ }^{1}$ Department of Anesthesiology, Nihon University School of Dentistry, Tokyo, Japan

${ }^{2}$ Department of Anesthesiology, Nihon University School of Medicine, Tokyo, Japan

\begin{abstract}
For patients with cardiac disorders and oral diseases who require surgery, oral treatment sometimes precedes cardiac surgery. We report management of general anesthesia for an oral surgery in a patient who had severe Aortic Stenosis (AS) and severe Mitral Regurgitation (MR) requiring cardiac surgery, a coexisting chronic renal failure on dialysis. The patient was a 56-year-old man diagnosed with severe AS and MR who had received hemodialysis for chronic renal failure. Due to coexisting severe periodontitis, dental caries, and radicular cysts, he received oral surgery under general anesthesia before cardiac surgery. Strict circulatory management was necessary for this patient. Arterial Pressure-Based Cardiac Output (APCO; Flo Trac/VigileoTM; Edwards Lifesciences, Irvine, CA, USA) was useful for more strict circulatory management of critical heart valve disease such as this patient.
\end{abstract}

Keywords: APCO (Arterial Pressure-Based Cardiac Output); General anesthesia; Heart valve disease; Cardiac surgery

\section{Introduction}

In cases of oral lesions in patients with valvular heart disease

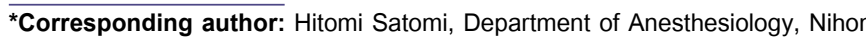
University School of Dentistry, Tokyo, Japan, Tel: +81 332198140; Fax: +81 332198357; E-mail: satomi.hitomi@nihon-u.ac.jp

Citation: Satomi H, Hirose N, Oka S, Oi Y (2020) General Anesthesia for an Oral Surgical Procedure in a Patient with Severe Heart Valve Disease Scheduled for Cardiac Surgery: A Case Report. J Anesth Clin Care 7: 055.

Received: August 15, 2020; Accepted: August 25, 2020; Published: September 02, 2020

Copyright: (c) 2020 Satomi $\mathrm{H}$, et al. This is an open-access article distributed under the terms of the Creative Commons Attribution License, which permits unrestricted use, distribution, and reproduction in any medium, provided the original author and source are credited. scheduled for a cardiac surgery, the oral treatment may be prioritized to prevent odontogenic infections [1]. We managed general anesthesia for an oral surgical procedure in a patient who was suffering from severe Aortic Stenosis (AS), severe Mitral Regurgitation (MR) and a coexisting chronic renal failure on dialysis. The patient was receiving maintenance dialysis and was scheduled for a cardiac surgery. In this case, strict intraoperative circulation management was necessary because the incidence of complications such as intraoperative death and nonfatal myocardial infarction in patients with severe AS undergoing noncardiac surgery is up to $31 \%$, the key points of circulation management for both severe AS and MR are different, and the excessive or insufficient intraoperative circulating blood volume tends to occur in patients on dialysis [2-5]. Accordingly, general anesthesia was well managed through an active intraoperative circulation evaluation with a detailed anesthesia plan and Arterial pressure-based cardiac output (APCO; Flo Trac/Vigileo ${ }^{\mathrm{TM}}$; Edwards Lifesciences, Irvine, CA, USA). We hereby present a report of this case.

\section{Case Report}

\section{Patient status}

The patient was a 56-year-old male with body height and body weight of $162.4 \mathrm{~cm}$ and $47.6 \mathrm{~kg}$, respectively. In terms of medical history, he was diagnosed with hypertension and a coexisting chronic renal failure on dialysis at 40 years of age and was receiving hemodialysis (3 times a week). Subsequently, at 55 years of age, he was diagnosed with AS and MR and scheduled for aortic and mitral valve replacement. He was prescribed with omeprazole, rebamipide, precipitated calcium carbonate, etizolam, triazolam, and mianserin hydrochloride and olmesartan medoxomil. His present dental condition included severe periodontitis and radicular cysts associated with both maxillary canines and the right maxillary first premolar and first molar as well as right mandibular second molar. Thus, he was scheduled for multiple tooth extraction and radicular cystectomy.

Preoperative Blood Pressure (BP) and Heart Rate (HR) at rest were $145 / 88 \mathrm{mmHg}$ and 98 beats/min, respectively. In addition, preoperative blood test showed the following abnormalities: Hemoglobin (Hb):10.1 g/dL, Hematocrit (Hct):9.8\%, Blood Urea Nitrogen (BUN):45.7 mg/dL, and Creatinine (Cr):10.18 mg/dL. Moreover, electrocardiography indicated left ventricular hypertrophy. He didn't have myocardium ischemia on the myocardial perfusion scintigraphy, and the pulmonary congestion was not detected in his chest X-ray (Figure 1). Transthoracic echocardiography revealed a left ventricular ejection fraction of $60 \%$. Wall motion disorder and heart failure were not confirmed, but the patient was diagnosed with severe AS and grade III MR (Figure 2) (Table 1). Although he did not have syncope history, he had exertional dyspnea. New York Heart Association functional classification was class II and American Society of Anesthesiologists physical status was class III, respectively. In this case, because his cardiac function was kept, we decided to prioritize the oral surgery to prevent postoperative endocarditis of aortic and mitral valve replacement [6]. 
Citation: Satomi H, Hirose N, Oka S, Oi Y (2020) General Anesthesia for an Oral Surgical Procedure in a Patient with Severe Heart Valve Disease Scheduled for Cardiac Surgery: A Case Report. J Anesth Clin Care 7: 55.
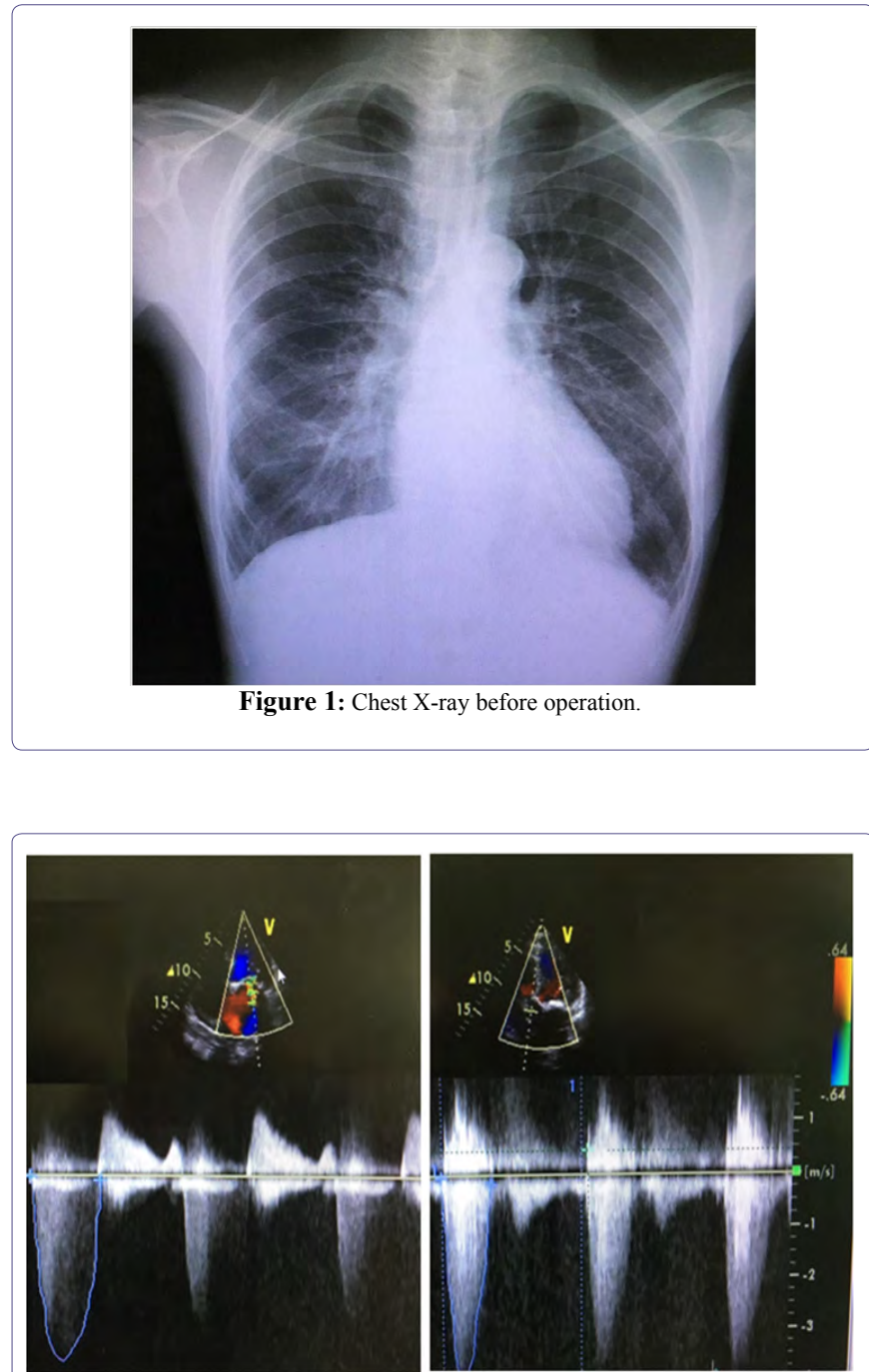

Figure 2: Echocardiography pictures of the aortic valve (light) and the mitral valve (left).

\section{Anesthesia Plan}

In this case, as fatal circulatory failure could have occurred intraoperatively, the procedure was performed under general anesthesia with local anesthesia to correspond with the strict intraoperative circulation management and resuscitation in such complication. To prevent endocarditis, cefazolin $1 \mathrm{~g}$ was used in intravenous administration preoperatively. Anesthesia was induced with fentanyl in divided administration as well as midazolam, and nasotracheal intubation was scheduled after the administration of rocuronium. For anesthesia maintenance, taking into consideration a coexisting chronic renal failure on dialysis, a continuous administration of remifentanil and sevoflurane was scheduled. Moreover, as the surgical field covered the full jaw and the amount of anesthetic used was predicted to be large, the local anesthetic selected was $1 \%$ lidocaine with 1:400000 adrenalines. Kalium-free infusion solution was used, and based on the amount of fluid removed during the preoperative dialysis, the maximum intraoperative dose was set at $800 \mathrm{ml}$. Additionally, in consultation with the nephrologist and cardiologist, the preoperative dialysis was performed 2 days before the operation while prioritizing the maintenance of the intraoperative circulating blood volume. In addition to 5-lead electrocardiography, the indirect and direct arterial BP and Central Venous Pressure (CVP); APCO, which can evaluate Cardiac Output (CO); Systemic Vascular Resistance (SVR); and Stroke Volume Variation (SVV), an indicator of the circulating blood volume, were used for circulation evaluation. Furthermore, to prepare for unexpected situations, we requested for emergency dialysis and a cardiologist to be on standby.

\section{Anesthesia Progress}

When entering the operation room, the patient's BP and HR were $160 / 85 \mathrm{mmHg}$ and 93 beats/min, respectively. Before anesthesia induction, an arterial-line was inserted into the right radial artery under local anesthesia following the circulation evaluation with APCO was initiated. Anesthesia was induced with $0.3 \mathrm{mg}$ fentanyl in divided administration and $3 \mathrm{mg}$ midazolam. Furthermore, the patient underwent nasotracheal intubation after the administration of $50 \mathrm{mg}$ of rocuronium. Hemodynamics were stable around the induction. After anesthesia induction, a central venous catheter was inserted into the right internal jugular vein, and the CVP was measured. Anesthesia was maintained with $2 \mathrm{~L} / \mathrm{min}$ of oxygen, 3 $\mathrm{L} / \mathrm{min}$ of air, $1.5 \%-3.0 \%$ sevoflurane, and $0.1-0.3 \mu \mathrm{g} / \mathrm{kg} / \mathrm{min}$ of remifentanil, and the partial pressure of end-tidal carbon dioxide was maintained at $40 \mathrm{mmHg}$ by controlled respiration. In addition, a total of $5.6 \mathrm{~mL}$ of local anesthetics was implemented to the upper and lower jaws and the procedure began. The intraoperative BP and HP were constantly stable at about $110 / 70 \mathrm{mmHg}$ and 60 beats/ min, respectively. However, during maxillary teeth extraction, these reduced to $70 / 38 \mathrm{mmHg}$ and 52 beats/min, respectively (Figure 3 ). In terms of the circulation indicators (Table 2(A)), SVV showed a low normal value; SVR, SVR index, and CVP were at the upper limit of the normal value; and SV, CO, and CI were at the lower limit of the normal value. Consequently, the circulating blood volume and SVR were well maintained, and the decrease in the $\mathrm{CO}$ was determined as the main factor of hypotension, so a total of $4 \mathrm{mg}$ of ephedrine was given with $2 \mathrm{mg}$ per administration. The circulation indicators $5 \mathrm{~min}$ after ephedrine administration are shown in table 2(B).

\begin{tabular}{|c|c|c|c|c|c|c|}
\hline Valve & Valve area $\left(\mathrm{cm}^{2}\right)$ & Mean pressure gradient $(\mathrm{mmHg})$ & $\begin{array}{c}\text { Peak pressure gradient } \\
(\mathrm{mmHg})\end{array}$ & $\begin{array}{l}\text { Regurgitant } \\
\text { volume (ml) }\end{array}$ & $\begin{array}{l}\text { Peak velocity }(\mathrm{cm} / \\
\text { sec) }\end{array}$ & $\begin{array}{l}\text { Effective regurgitant } \\
\text { orifice area }\left(\mathbf{c m}^{2}\right)\end{array}$ \\
\hline Aortic valve & 0.62 & 42.2 & 82.4 & None & 453.9 & None \\
\hline \multirow{2}{*}{ Mitral valve } & 1.68 & None & None & 62 & None & 0.41 \\
\hline & \multicolumn{6}{|c|}{ The mobility of the anterior cusp is barely kept. } \\
\hline
\end{tabular}

Table 1: Echocardiographic findings of the aortic and mitral valves.

Severe Aortic Stenosis (AS): Valve area $<0.6 \mathrm{~cm}^{2}$, Mean pressure gradient $\geqq 40 \mathrm{mmHg}$, Peak velocity $\geqq 400 \mathrm{~cm} / \mathrm{sec}$.

Severe mitral Regurgitation (MR): Regurgitant volume $\geqq 60 \mathrm{ml}$, Effective regurgitant orifice area $\geqq 0.4 \mathrm{~cm}^{2}$. 
Citation: Satomi H, Hirose N, Oka S, Oi Y (2020) General Anesthesia for an Oral Surgical Procedure in a Patient with Severe Heart Valve Disease Scheduled for Cardiac Surgery: A Case Report. J Anesth Clin Care 7: 55.

Hemodynamics was stable until the end of the procedure, anesthesia awakening was good, and the patient was sent to the intensive care unit after extubation. The surgery and anesthesia durations were $130 \mathrm{~min}$ and $225 \mathrm{~min}$, respectively. The total infusion and bleeding volumes were $450 \mathrm{~mL}$ and $127 \mathrm{~g}$, respectively. The postoperative course was good, and the patient was temporarily discharged 4 days later, with a heart valve replacement scheduled in 2 months.

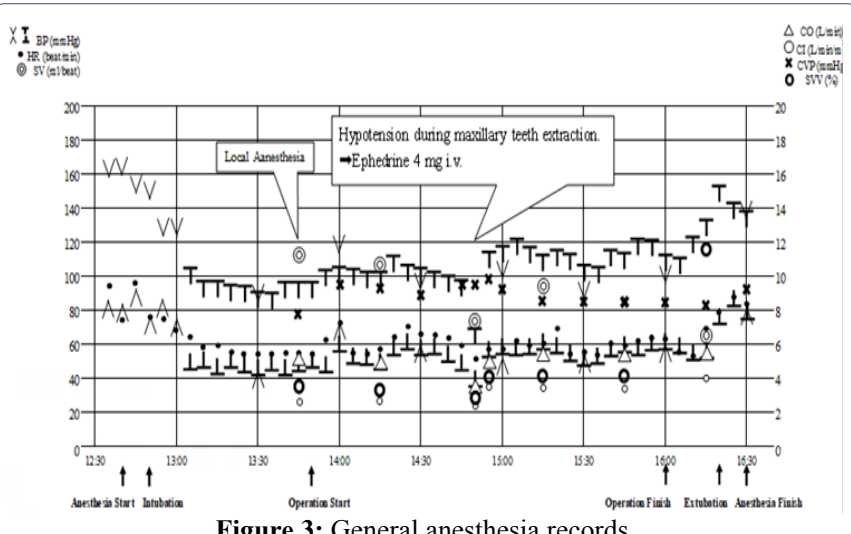

Figure 3: General anesthesia records.

BP: Blood Pressure (invasive or non-invasive), HR: Heart Rate, SV: Stroke Volume,

CO: Cardiac Output, CI: Cardiac Index, CVP: Central Venous Pressure, SVV: Stroke Volume Variation.

\begin{tabular}{|c|c|c|}
\hline Hemodynamic parameter & A & B \\
\hline Blood pressure (systolic/diastolic, $\mathrm{mmHg})$ & $70 / 38$ & $115 / 55$ \\
\hline Heat rate (beats/min) & 52 & 59 \\
\hline Stroke volume (mL/beat) & 76.9 & 91.5 \\
\hline Cardiac output $(\mathrm{L} / \mathrm{min})$ & 4 & 5.4 \\
\hline Cardiac index $\left(\mathrm{L} / \mathrm{min} / \mathrm{m}^{2}\right)$ & 2.6 & 3.5 \\
\hline Stroke volume variation (\%) & 4 & 6 \\
\hline Systemic vascular resistance (dynes $\left./ \mathrm{sec} / \mathrm{cm}^{5}\right)$ & 1480 & 1615 \\
\hline Systemic vascular resistance index $\left(\right.$ dynes $\left./ \mathrm{sec} / \mathrm{cm}^{2} / \mathrm{m}^{2}\right)$ & 2200 & 2400 \\
\hline Central venous pressure $(\mathrm{mmHg})$ & 10 & 11 \\
\hline
\end{tabular}

Table 2: Hemodynamics at hypotension onset and 5 min after ephedrine administration.

A: At the time of hypotension onset.

B: Five min after ephedrine administration.

\section{Discussion}

The occurrence rate of Infective Endocarditic (IE) has been reported to be 3-10 per 100,000 people, among which $10 \%-20 \%$ are related to oral bacteria $[7,8]$. Therefore, dental treatment before cardiac surgery is important for the infective endocarditic prevention [1]. In this case, we also prioritized oral surgery over cardiac surgery and performed it under general anesthesia.

Anesthesia risk for this patient was severe AS and MR as well as a coexisting chronic renal failure on dialysis. The patients with AS are prone to myocardial ischemia due to the hypotension-induced decrease in the coronary flow, so the SVR should not be reduced. In addition, 50-70 beats/min HR value is desirable to maintain the systolic time when passing through the stenosed aortic valve [3].
Contrarily, the patients with MR have a higher risk of heart failure due to a $\mathrm{CO}$ decrease of the systemic circulation since an increase of the regurgitation volume by bradycardia and afterload increase. Therefore, it is necessary to keep the SVR low and maintain the $\mathrm{HR}$ at a normal to rather high value [3]. And, to keep the CO in the case of AS and MR, it is important to maintain the myocardial contraction. Due to preoperative dialysis and infusion restrictions, patients on dialysis are prone to excessive or insufficient circulating blood volume, which is a significant regulatory factor of circulation [5]. Based on the aforementioned, it was necessary to individually evaluate the circulation parameters, such as $\mathrm{CO}, \mathrm{SVR}$, and circulating blood volume, for the circulation management in this case.

In this case, BP decreased during the operation. Usually, when dealing with hypotension in the cases of combined AS and MR, AS is prioritized, which tends to be more fatal, and the first intervention is to administer $\alpha$-stimulants, such as phenylephrine, to maintain SVR [4]. Meanwhile, at the low blood pressure in this case, based on the circulation evaluation with APCO, we were able to judge the $\mathrm{CO}$ drop due to the myocardial contraction drop, and the addition of infusion and phenylephrine administration has been avoided, and the intervention for hypotension through ephedrine administration was selected. Aside from BP recovery, SV, CO, and CI increased to appropriate values, and based on these results, we could be inferred that the selection of intervention for hypotension was appropriate. The indications of APCO for various valvular diseases have been widely discussed, but the respective effectiveness of AS and MR has been previously reported $[9,10]$, circulation evaluation with the APCO in the cases of combined AS and MR seemed to be effective.

In principle, preoperative dialysis is performed on the day before the surgery [4]. However, in this case, because the scheduled surgery time was short and the possibility of both intraoperative fluid overload and blood transfusion were low, the priority was given to the prevention of intraoperative circulatory failure due to excessive circulating blood volume insufficiency. Thus, preoperative dialysis was performed 2 days before the operation. This judgement would contribute to the maintenance of the sufficient intraoperative circulating blood volume in CVP and SVV evaluation.

To avoid the effects of adrenaline on the circulation as much as possible, 1\% lidocaine with adrenaline content adjusted to 1:400000 was used for local anesthesia in this case. However, for patients suffering from circulatory system diseases, $2 \%$ lidocaine with 1:200000 adrenalines has been recommended as the local anesthetic to prevent its effects on the cardiovascular system while achieving sufficient hemostatic and anesthetic effects [11]. Thus, a thorough and detailed discussion might be necessary, including the advisability of adrenaline use in the selection of local anesthetics, with the surgeon before the operation.

In conclusion, for patient with cardiac disorders and oral diseases, dental treatment before cardiac surgery is significant for the IE prevention. We managed general anesthesia for an oral surgical procedure in a patient with a coexisting chronic renal failure on dialysis and severe heart valve diseases scheduled for a cardiac surgery. It was well managed through a detailed anesthesia plan and strict intraoperative circulation evaluation with APCO for this patient. 


\section{Acknowledgment}

This study was supported by Sato Fund, Nihon University School of Dentistry.

\section{References}

1. Souza AF, Rocha AL, Castro WH, Ferreira FM, Gelape CL, et al. (2016) Dental care before cardiac valve surgery: is it important to prevent infective endocarditis? Int J Cardiol Heart Vasc 12: 57-62.

2. Kertai MD, Bountioukos M, Boersma E, Bax JJ, Thomson IR, et al. (2004) Aortic stenosis: an underestimated risk factor for Perioperative complications in patients undergoing noncardiac surgery. Am J Med 116: 8-13.

3. Paul A, Das S (2017) Valvular heart disease and anaethesia. Indian J Anaesth 61: 721-727.

4. Christ M, Sharkova Y, Geldner G, Maisch B (2005) Preoperative and perioperative care for patients with suspected or established aortic stenosis facing noncardiac surgery. Chest 128: 2944-2953.

5. Kanda H, Hirasaki Y, Iida T, Kanao-kanda M, Toyama Y, et al. (2017) Perioperative management of patients with end-stage renal disease. J Cardiothorac Vasc Anesth 31: 2251-2267.
6. Kyo S, Imanaka K, Masuda M, Miyata T, Morita K, et al. (2017) Guidelines for Perioperative Cardiovascular Evaluation and Management for Noncardiac Surgery (JCS 2014). Circ J 81: 245-267.

7. Selton-Suty C, Célard M, Moing VL, Doco-Lecompte T, Chirouze C, et al. (2012) Preeminence of staphylococcus aureus in infective endocarditis: a 1-year population-based survey. Clin Infect Dis 54: 1230-1239.

8. Rosa MRM, Cosano LC, Perez MJR, Cutando A (2014) The bacteremia of dental origin and its implications in the appearance of bacterial endocarditis. Med Oral Patol Oral Cir Bucal 19: 67-73.

9. Lorsomradee S, Lorsomradee S, Cromheecke S, De Hert SG (2007) Uncalibrated arterial pulse contour analysis versus continuous thermodilution technique: effects of alterations in arterial waveform. J Cardiothorac Vasc Anesth 21: 636-643.

10. Tamura T, Yatabe T, Yamashita K, Yokoyama M (2013) Management of anesthesia for pheochromocytoma in a patient complicated with severe mitral regurgitation. The Journal of Japan Society for Clinical Anesthesia 33: $815-819$.

11. Karm MH, Kim M, Park FD, Seo KS, Kim HJ (2018) Comparative evolution of the efficacy, safety, and hemostatic effect of $2 \%$ lidocaine with various concentration of epinephrine. J Dent Anesth Pain Med 18: 143-149. 


\section{If}

Advances In Industrial Biotechnology | ISSN: 2639-5665

Advances In Microbiology Research | ISSN: 2689-694X

Archives Of Surgery And Surgical Education | ISSN: 2689-3126

Archives Of Urology

Archives Of Zoological Studies | ISSN: 2640-7779

Current Trends Medical And Biological Engineering

International Journal Of Case Reports And Therapeutic Studies | ISSN: 2689-310X

Journal Of Addiction \& Addictive Disorders | ISSN: 2578-7276

Journal Of Agronomy \& Agricultural Science | ISSN: 2689-8292

Journal Of AIDS Clinical Research \& STDs | ISSN: 2572-7370

Journal Of Alcoholism Drug Abuse \& Substance Dependence | ISSN: 2572-9594

Journal Of Allergy Disorders \& Therapy | ISSN: 2470-749X

Journal Of Alternative Complementary \& Integrative Medicine | ISSN: 2470-7562

Journal Of Alzheimers \& Neurodegenerative Diseases | ISSN: 2572-9608

Journal Of Anesthesia \& Clinical Care | ISSN: 2378-8879

Journal Of Angiology \& Vascular Surgery | ISSN: 2572-7397

Journal Of Animal Research \& Veterinary Science | ISSN: 2639-3751

Journal Of Aquaculture \& Fisheries | ISSN: 2576-5523

Journal Of Atmospheric \& Earth Sciences | ISSN: 2689-8780

Journal Of Biotech Research \& Biochemistry

Journal Of Brain \& Neuroscience Research

Journal Of Cancer Biology \& Treatment | ISSN: 2470-7546

Journal Of Cardiology Study \& Research | ISSN: 2640-768X

Journal Of Cell Biology \& Cell Metabolism | ISSN: 2381-1943

Journal Of Clinical Dermatology \& Therapy | ISSN: 2378-8771

Journal Of Clinical Immunology \& Immunotherapy | ISSN: 2378-8844

Journal Of Clinical Studies \& Medical Case Reports | ISSN: 2378-8801

Journal Of Community Medicine \& Public Health Care | ISSN: 2381-1978

Journal Of Cytology \& Tissue Biology | ISSN: 2378-9107

Journal Of Dairy Research \& Technology | ISSN: 2688-9315

Journal Of Dentistry Oral Health \& Cosmesis | ISSN: 2473-6783

Journal Of Diabetes \& Metabolic Disorders | ISSN: 2381-201X

Journal Of Emergency Medicine Trauma \& Surgical Care | ISSN: 2378-8798

Journal Of Environmental Science Current Research | ISSN: 2643-5020

Journal Of Food Science \& Nutrition | ISSN: 2470-1076

Journal Of Forensic Legal \& Investigative Sciences | ISSN: 2473-733X

Journal Of Gastroenterology \& Hepatology Research | ISSN: 2574-2566
Journal Of Genetics \& Genomic Sciences | ISSN: 2574-2485

Journal Of Gerontology \& Geriatric Medicine | ISSN: 2381-8662

Journal Of Hematology Blood Transfusion \& Disorders | ISSN: 2572-2999

Journal Of Hospice \& Palliative Medical Care

Journal Of Human Endocrinology | ISSN: 2572-9640

Journal Of Infectious \& Non Infectious Diseases | ISSN: 2381-8654

Journal Of Internal Medicine \& Primary Healthcare | ISSN: 2574-2493

Journal Of Light \& Laser Current Trends

Journal Of Medicine Study \& Research | ISSN: 2639-5657

Journal Of Modern Chemical Sciences

Journal Of Nanotechnology Nanomedicine \& Nanobiotechnology | ISSN: 2381-2044

Journal Of Neonatology \& Clinical Pediatrics | ISSN: 2378-878X

Journal Of Nephrology \& Renal Therapy | ISSN: 2473-7313

Journal Of Non Invasive Vascular Investigation | ISSN: 2572-7400

Journal Of Nuclear Medicine Radiology \& Radiation Therapy | ISSN: 2572-7419

Journal Of Obesity \& Weight Loss | ISSN: 2473-7372

Journal Of Ophthalmology \& Clinical Research | ISSN: 2378-8887

Journal Of Orthopedic Research \& Physiotherapy | ISSN: 2381-2052

Journal Of Otolaryngology Head \& Neck Surgery | ISSN: 2573-010X

Journal Of Pathology Clinical \& Medical Research

Journal Of Pharmacology Pharmaceutics \& Pharmacovigilance | ISSN: 2639-5649 Journal Of Physical Medicine Rehabilitation \& Disabilities | ISSN: 2381-8670

Journal Of Plant Science Current Research | ISSN: 2639-3743

Journal Of Practical \& Professional Nursing | ISSN: 2639-5681

Journal Of Protein Research \& Bioinformatics

Journal Of Psychiatry Depression \& Anxiety | ISSN: 2573-0150

Journal Of Pulmonary Medicine \& Respiratory Research | ISSN: 2573-0177

Journal Of Reproductive Medicine Gynaecology \& Obstetrics | ISSN: 2574-2574

Journal Of Stem Cells Research Development \& Therapy | ISSN: 2381-2060

Journal Of Surgery Current Trends \& Innovations | ISSN: 2578-7284

Journal Of Toxicology Current Research | ISSN: 2639-3735

Journal Of Translational Science And Research

Journal Of Vaccines Research \& Vaccination | ISSN: 2573-0193

Journal Of Virology \& Antivirals

Sports Medicine And Injury Care Journal | ISSN: 2689-8829

Trends In Anatomy \& Physiology | ISSN: 2640-7752

Submit Your Manuscript: https://www.heraldopenaccess.us/submit-manuscript 